\title{
Desempenho e rendimento de carcaça de frangos de corte alimentados com dietas contendo subprodutos do arroz formuladas com base nos conceitos de proteína bruta e ideal ${ }^{1}$
}

\author{
Luciana Cardoso Cancherini ${ }^{2 *}$, Karina Ferreira Duarte ${ }^{3}$, Otto Mack Junqueira ${ }^{4}$, Rosemeire da \\ Silva Filardi ${ }^{5}$, Antônio Carlos de Laurentiz ${ }^{5}$, Lúcio Francelino Araújo ${ }^{6}$ \\ ${ }^{1}$ Projeto financiado pela Fapesp (Proc. 03/01989-4). \\ 2 Departamento de Zootecnia, Universidade do Estado de Mato Grosso, Campus Universitário de Pontes e Lacerda, Pontes e Lacerda, MG. \\ ${ }^{3}$ Curso de Pós-graduação da Universidade Estadual Paulista Júlio de Mesquita Filho, Faculdade de Ciências Agrárias e Veterinárias de \\ Jaboticabal - UNESP. \\ ${ }^{4}$ Departamento de Zootecnia da Universidade Estadual Paulista Júlio de Mesquita Filho, Faculdade de Ciências Agrárias e Veterinárias de \\ Jaboticabal - UNESP. \\ ${ }^{5}$ Departamento de Biologia e Zootecnia da Universidade Estadual Paulista Júlio de Mesquita Filho, Faculdade de Engenharia de Ilha Solteira \\ - UNESP. \\ ${ }^{6}$ Departamento de Zootecnia da Universidade de São Paulo (USP), Faculdade de Zootecnia e Engenharia de Alimentos - FZEA \\ Pirassununga, SP.
}

RESUMO - Foi conduzido um experimento para avaliar a utilização de subprodutos do arroz em dietas formuladas com base nos conceitos de proteína bruta e ideal para frangos de corte de 1 a 42 dias de idade. Foram utilizados 720 pintos machos de 1 dia de idade da linhagem "Hybro", em delineamento inteiramente ao acaso, em esquema fatorial $3 \times 2$, composto de três dietas (sem subprodutos, farelo de arroz integral e quirera de arroz) e dois conceitos de formulação de rações (proteína bruta e ideal), totalizando seis tratamentos e quatro repetições de 30 aves. O ganho de peso, o consumo de ração e a conversão alimentar foram avaliados aos 21 e 42 dias e as características de carcaça aos 42 dias de idade. As aves alimentadas com dietas formuladas pelo conceito tradicional (baseado na proteína bruta) apresentaram melhor conversão alimentar e menor taxa de deposição de gordura abdominal.

Palavras-chave: aminoácidos digestíveis, desempenho, farelo de arroz integral, quirera de arroz

\section{Performance and carcass yield of broilers fed diets containing rice by- products, formulated based on crude and ideal protein concepts}

ABSTRACT - One experiment was conducted to evaluate the utilization of rice by-products in diets based on crude and ideal protein concepts for broilers from 1 to 42 days of age. Seven hundred and twenty male chicks, one day old, Hybro strain, were distributed in a completely randomized design in a $3 \times 2$ factorial arrangment, three diets (without by-product, whole rice meal and broken rice) and two ration formulation concepts (crude and ideal protein), totalizing six treatments and four replications of 30 birds. Weight gain, feed intake and feed:gain ratio were evaluated at 21 and 42 days, and carcass characteristics at 42 days of age. In conclusion, birds fed diets formulated by the traditional concept (based on crude protein) showed better feed:gain ratio and lower deposition rate of abdominal fat.

Key Words: broken rice, digestible amino acids, performance, whole rice meal

\section{Introdução}

O uso de alimentos alternativos tem se tornado mais freqüente nos últimos anos. A expectativa de que o milho e o farelo de soja sejam mais direcionados para o consumo humano e a busca na redução de custos da alimentação têm impelido os nutricionistas a estudarem outras opções alimentares. Por outro lado, a formulação de rações de acordo com valores de aminoácidos digestíveis em detrimento aos valores de aminoácidos totais tem possibilitado resultados satisfatórios e melhora na produtividade. Segundo Emmert \& Baker (1997), a proteína ideal pode ser definida como o balanceamento exato dos aminoácidos, sem deficiências ou sobras, com o objetivo de satisfazer os requisitos de todos os aminoácidos para mantença e ganho máximo de proteína corporal, reduzindo o uso de 
aminoácidos como fonte de energia e diminuindo a excreção de nitrogênio.

Com o objetivo de avaliar o desempenho de frangos de corte alimentados com dietas formuladas com base em proteína ideal ou bruta, Araújo et al. (2001) verificaram que a proteína ideal resultou em melhor ganho de peso e maior consumo de ração e não teve efeito sobre a conversão alimentar. Bregendahl et al. (2002), ao reduzirem o nível protéico da dieta inicial de 23 para 19\%, observaram redução do desempenho das aves e relataram que frangos de corte nesta fase são mais sensíveis a variações nos níveis protéicos da dieta. Por outro lado, Hussein et al. (2001), comparando dietas com 23 e 17,7\% de proteína bruta para frangos de corte na fase inicial suplementadas com aminoácidos essenciais, verificaram redução no ganho de peso, aumento no consumo de ração e piora na conversão alimentar com a redução do nível de proteína bruta.

O conceito de formulação com base nos aminoácidos digestíveis é mais interessante quando se utilizam os ingredientes alternativos, por serem uma opção de substituição parcial ou integral às fontes tradicionais de energia e proteína. Como os preços dos ingredientes convencionais estão constantemente variando, os alternativos tornam-se uma opção economicamente viável. Um alimento alternativo de grande destaque para a alimentação de animais é o farelo de arroz integral, produzido em grandes quantidades no País, e a quirera de arroz, ainda pouco utilizada na alimentação de frangos de corte.

O objetivo neste trabalho foi avaliar a utilização do farelo de arroz integral e da quirera de arroz em dietas formuladas com base nas proteínas bruta e ideal para frangos de corte de 1 a 42 dias de idade.

\section{Material e Métodos}

Foram alojados 720 pintos machos de 1 dia de idade da linhagem "Hybro", com peso inicial médio de 42,5 g, em galpão convencional de alvenaria com cama de maravalha. O delineamento experimental foi inteiramente casualizado em esquema fatorial $3 \times 2$, composto de três dietas (AS - sem subproduto; FAI - com farelo de arroz integral; e QA - com quirera de arroz) e dois conceitos de formulação de rações (proteína bruta e proteína ideal), totalizando seis tratamentos e quatro repetições de 30 aves.

As dietas experimentais (Tabelas 1 e 2 ) utilizadas no período de 1 a 21 e 22 a 42 dias de idade foram isocalóricas e isonutritivas e formuladas com base nos conceitos de proteínas bruta (PB) e ideal (PI) segundo Rostagno et al. (2000). Os subprodutos (farelo de arroz e quirera de arroz) foram analisados quanto à composição química, energia metabolizável e os aminoácidos digestíveis antes da formulação das dietas experimentais e incluídos nos níveis de 6,5 e $5,0 \%$ (FAI) e 22,5\% e 7,5\% (QA) para os períodos de 1 a 21 e 22 a 42 dias de idade, respectivamente.

Os coeficientes de digestibilidade verdadeira dos aminoácidos dos ingredientes foram obtidos com galos Legorne adultos, cecectomizados, utilizando-se a metodologia da alimentação forçada, descrita por Sibbald (1976). Foram determinados os coeficientes de digestibilidade verdadeira de cada aminoácido, com base nos resultados das análises de aminoácidos ingeridos e excretados e do endógeno obtido, com galos em jejum, utilizando-se a fórmula descrita por Rostagno \& Featherston (1977).

Os valores de matéria seca (MS), proteína bruta (PB), extrato etéreo (EE), fibra bruta (FB), energia metabolizável aparente (EMA) e aparente corrigida (EMAn) foram, respectivamente, $88,6 \% ; 11,79 \% ; 15,30 \% ; 10,20 \%$; $2.968 \mathrm{kcal} / \mathrm{kg}$ e $2.804 \mathrm{kcal} / \mathrm{kg}$ para o FAI e $93,52 \%$; 9,11\%; 0,73\%; 0,45\%; $3.338 \mathrm{kcal} / \mathrm{kg} ; 3.239 \mathrm{kcal} / \mathrm{kg}$ para a quirera de arroz. Os valores médios dos coeficientes de digestibidade dos aminoácidos essenciais e não-essenciais foram, respectivamente, 75,91 e 73,92\% para o FAI e 77,88 e 76,50\% para a quirera de arroz.

Aos 21 e 42 dias de idade, as aves e a ração foram pesadas para determinação do ganho de peso, do consumo de ração e da conversão alimentar. Após as pesagens aos 42 dias de idade, três aves de cada unidade experimental foram mantidas em jejum alimentar (6 horas) e abatidas. Após a evisceração, as carcaças (sem cabeça e pescoço, pés e gordura abdominal) foram pesadas e a gordura abdominal foi retirada e pesada juntamente com a gordura aderida à moela e ao proventrículo. O rendimento de carcaça foi calculado em função do peso ao abate e os rendimentos dos cortes e o peso relativo da gordura abdominal foram determinados considerando o peso da carcaça limpa e eviscerada.

Calculou-se para o período total ( 1 a 42 dias) o custo com ração/kg vivo de frango. Os custos das dietas foram calculados considerando a variação mensal da matériaprima. As análises estatísticas foram realizadas utilizando-se o programa SAEG e as médias foram comparadas pelo teste Tukey (Euclydes, 1997) a 5\% de probabilidade. 
Tabela 1 - Composição das rações experimentais na fase de 1 a 21 dias de idade

\begin{tabular}{|c|c|c|c|c|c|c|}
\hline Item & \multicolumn{3}{|c|}{ Proteína bruta } & \multicolumn{3}{|c|}{ Proteína ideal ${ }^{5}$} \\
\hline \multicolumn{7}{|l|}{ Ingrediente } \\
\hline Milho grão & 56,25 & 49,39 & 33,18 & 62,30 & 55,65 & 39,70 \\
\hline Farelo de soja & 36,40 & 36,20 & 36,45 & 31,00 & 30,65 & 30,80 \\
\hline Farelo de arroz ${ }^{1}$ & - & 6,50 & - & - & 6,50 & - \\
\hline Fosfato bicálcico & 1,80 & 1,75 & 1,84 & 1,84 & 1,76 & 1,88 \\
\hline Calcário calcítico & 0,98 & 1,00 & 0,96 & 1,00 & 1,02 & 1,00 \\
\hline Sal & 0,45 & 0,45 & 0,45 & 0,46 & 0,46 & 0,46 \\
\hline Suplemento mineral ${ }^{3}$ & 0,25 & 0,25 & 0,25 & 0,25 & 0,25 & 0,25 \\
\hline Suplemento vitamínico ${ }^{4}$ & 0,45 & 0,45 & 0,45 & 0,45 & 0,45 & 0,45 \\
\hline L-lisina $\mathrm{HCl}(78,8 \%)$ & 0,14 & 0,12 & 0,10 & 0,30 & 0,28 & 0,27 \\
\hline EM (kcal/kg) & 3.000 & 3.000 & 3.000 & 3.000 & 3.000 & 3.000 \\
\hline PB (\%) & 21,50 & 21,50 & 21,50 & 19,50 & 19,50 & 19,50 \\
\hline $\mathrm{Ca}(\%)$ & 0,960 & 0,960 & 0,960 & 0,960 & 0,960 & 0,960 \\
\hline P disponível (\%) & 0,450 & 0,450 & 0,450 & 0,450 & 0,450 & 0,450 \\
\hline $\mathrm{Na}(\%)$ & 0,222 & 0,222 & 0,222 & 0,222 & 0,222 & 0,222 \\
\hline Lisina total $(\%)$ & 1,263 & 1,263 & 1,263 & 1,166 & 1,166 & 1,166 \\
\hline Lisina digestível (\%) & 1,238 & 1,238 & 1,238 & 1,143 & 1,143 & 1,143 \\
\hline Metionina total (\%) & 0,492 & 0,492 & 0,492 & 0,458 & 0,458 & 0,458 \\
\hline Metionina digestível (\%) & 0,477 & 0,477 & 0,477 & 0,444 & 0,444 & 0,444 \\
\hline Metionina + Cistina (\%) & 0,950 & 0,950 & 0,950 & 0,830 & 0,830 & 0,830 \\
\hline Met + Cis digestível (\%) & 0,840 & 0,840 & 0,840 & 0,809 & 0,809 & 0,809 \\
\hline Treonina total (\%) & 0,834 & 0,834 & 0,834 & 0,774 & 0,774 & 0,774 \\
\hline Treonina digestível (\%) & 0,723 & 0,723 & 0,723 & 0,675 & 0,675 & 0,675 \\
\hline
\end{tabular}

* SA: sem subproduto; FAl: farelo de arroz integral; QA: quirera de arroz.

1 PB - 11,79\%; Ca - 0,14\%; 0,97 Pt; 10,20\% FB e 2.804 kcal/kg EMA.

2 PB - 9,11\%; Ca - 0,03\%; Pt - 0,19\%; FB - 0,45\%; EMA - $3.239 \mathrm{kcal} / \mathrm{kg}$.

3 Enriquecido por kg de ração: Cu - 31,25 mg; Fe - 37,5 mg; Mn - 75 mg; Zn - 62,50 mg; I 1 mg I; Se - 0,175 mg.

${ }^{4}$ Enriquecido por kg de ração: vit. $A-12.000$ UI; vit. $D_{3}-2.250 \mathrm{UI}$; vit. $E-1,8$ mg; vit. $\mathrm{K}_{3}-1,8 \mathrm{mg}$; vit. $\mathrm{B}_{1}-2,0 \mathrm{mg}$; vit. $\mathrm{B}_{2}-2,0 \mathrm{mg}$; vit. $\mathrm{B}_{12}-35 \mathrm{mcg}$ piridoxina - 0,4 mg; ácido fólico - 0,4 mg; biotina - 0,09 mg; ácido nicotínico - 38,0 mg; ácido pantotênico - $912 \mathrm{mg}$; colina - 0,675 g; metionina - 1,35 g; agente anticoccidiano - 0,495 g; antibiótico - 0,18 g; antioxidante BHT - 0,09 g.

5 Relação lisina:aminoácido: lisina 1,143 (100\%); 0,444 (39\%); 0,675 (59\%).

6 De acordo com Rostagno et al. (2000). 
Tabela 2 - Composição das rações fornecidas na fase de 22 a 42 dias de idade

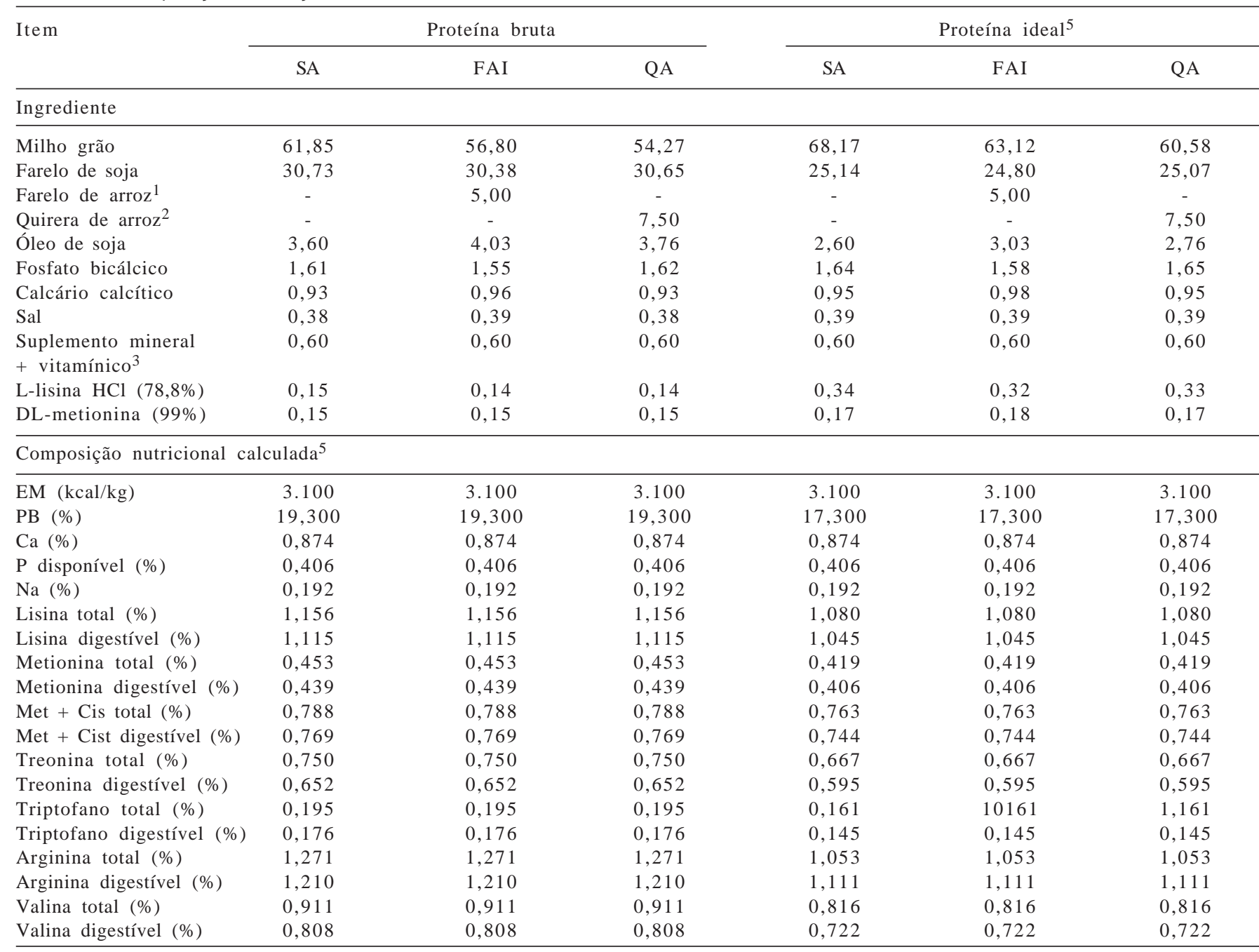

SA: sem subproduto; FAl: farelo de arroz integral; QA: quirera de arroz.

1 PB - 9\%; Ca - 0,14\%; P total - 0,97; FB - 10,20\%; EMA - $2.804 \mathrm{kcal} / \mathrm{kg}$

2 PB - 9,11\%; Ca - 0,03\%; P total - 0,19\%; FB - 0,45\%; EMA - $3.239 \mathrm{kcal} / \mathrm{kg}$.

${ }^{3}$ Enriquecido por kg de ração: $\mathrm{Cu}$ - 31,25 mg; Fe - 37,5 mg; Mn - 75 mg; Zn - 62,50 mg; I - 1 mg I; Se - 0,175 mg Se.

4 Enriquecido por kg de ração ração: vit. A - 8.000 UI; vit. $D_{3}-1.800$ UI; vit. E - 12 mg; vit. $\mathrm{K}_{3}-2$ mg; vit. $B_{1}-1$ mg; vit. B -4 mg; vit. $B_{6}-1$ mg; vit. $\mathrm{B}_{12}$ - $10 \mathrm{mcg}$; ácido fólico - 0,40 mg; biotina - 0,04 mg; niacina - $28 \mathrm{mg}$; pantotenato de cálcio - $11 \mathrm{mg}$; Cu - $6 \mathrm{mg}$; Co - 0,10 mg; I $1 \mathrm{mg}$; Fe 50 mg; Mn - 65 mg; Zn - 45 mg; Se - 0,21 mg; cloreto de colina 50\% - 500 mg; metionina - 1.400 mg; agente anticoccidiano - 60 mg; antibiótico - 60 mg; antioxidante BHT - $12 \mathrm{mg}$.

5 Relação lisina:aminoácido; Lisina - 1,045 (100\%); 0,406 (39\%); 0,595 (57\%).

${ }^{6}$ De acordo com Rostagno et al. (2000).

\section{Resultados e Discussão}

Não houve diferença estatística $(\mathrm{P}>0,05)$ no consumo de ração e no ganho de peso atribuída à inclusão dos subprodutos, ao conceito de formulação e à interação desses fatores (Tabela 3).

As aves alimentadas com as dietas formuladas com base no conceito de proteína ideal apresentaram piora $(\mathrm{P}<0,05)$ na conversão alimentar em relação àquelas alimentadas com dietas formuladas com base no teor de proteína bruta (PB), provavelmente em virtude do menor conteúdo protéico e da conseqüente diminuição de nitrogênio livre, que determina menor conversão de aminoácidos essenciais em aminoácidos não-essenciais, comprometendo o desempenho da ave (Keshavarz \& Jackson, 1992). Efeito semelhante foi observado por Faria Filho (2006) em frangos de corte no período de 7 a 21 dias de idade alimentados com dietas com baixo teor protéico (18,5 e 20\%) formuladas com base no conceito de proteína ideal e suplementadas com aminoácidos sintéticos. Observou-se melhora na conversão alimentar quando os frangos foram alimentados com dietas formuladas com 21,5\% PB; esses resultados diferem dos observados por Cancherini (2005), que avaliou dietas com subprodutos de origem animal para frangos de corte até 21 dias de idade e não observou efeito sobre esta característica. 
Tabela 3 - Desempenho de frangos de corte alimentados com dietas contendo subprodutos do arroz formuladas com base nos conceitos de proteína bruta e ideal na fase de1 a 21 dias de idade

\begin{tabular}{lccc}
\hline \multirow{2}{*}{ Item } & \multicolumn{3}{c}{ Característica avaliada } \\
\cline { 2 - 4 } & CR (g) & GP (g) & CA \\
\hline Proteína & 1.185 & 838 & $1,41 \mathrm{~b}$ \\
Bruta & 1.205 & 827 & $1,46 \mathrm{a}$ \\
Ideal & & & \\
\hline Subproduto do arroz & & 832 & 1,45 \\
SA & 1.207 & 817 & 1,43 \\
FAI & 1.171 & 848 & 1,42 \\
QA & 1.206 & Valor de F \\
\hline & & $1,41^{\mathrm{ns}}$ & $6,93^{*}$ \\
\hline Proteína (Ptn) & $1,44^{\mathrm{ns}}$ & $3,67^{\mathrm{ns}}$ & $0,93^{\mathrm{ns}}$ \\
Subproduto do arroz (S) & $2,26^{\mathrm{ns}}$ & $0,15^{\mathrm{ns}}$ & $1,10^{\mathrm{ns}}$ \\
Ptn $\times$ S & $0,60^{\mathrm{ns}}$ & 2,52 & 2,51 \\
\hline CV (\%) & 3,06 & & \\
\hline
\end{tabular}

CR: consumo de ração; GP: ganho de peso; CA: conversão alimentar; SA: sem subproduto; FAl: farelo de arroz integral; QA: quirera de arroz. Médias na coluna seguidas de letras minúsculas diferentes são significativas $(P<0,05)$ pelo teste Tukey. ${ }^{*} \mathrm{P}<0,05$.

Quando alimentadas com dietas contendo 21,5\% PB formuladas com base em aminoácidos totais, as aves apresentaram mesmo consumo de ração e ganho de peso daquelas alimentadas com dietas contendo 19,5\% PB formuladas com base em aminoácidos digestíveis.

Trabalhos de Pinchasov et al. (1990), Summers et al. (1992a), Fergunson et al. (1998), Araújo et al. (2001) e Araújo et al. (2004) comprovaram que a redução do teor de PB da dieta não afeta o consumo de ração, observação confirmada neste experimento. Segundo Gonzales (2002), o controle do consumo não decorre somente da quantidade da PB, mas também de sua qualidade, isto é, da concentração e do balanceamento dos aminoácidos. Os resultados obtidos neste experimento diferem dos relatados por Costa et al. (2001) e Bregendahl et al. (2002), que observaram aumento no consumo de ração de frangos de corte machos quando houve diminuição do nível protéico da dieta.

O consumo de ração, o ganho de peso e a conversão alimentar não foram afetados $(\mathrm{P}>0,05)$ pelos níveis de FAI, o que contraria os resultados descritos por Gallinger et al. (2004), que, ao fornecerem dietas com 0, 10 e 20\% de FAI para frangos de corte de 1 a 21 dias de idade, observaram menor ganho de peso (3,93\%) dos frangos alimentados com dietas com FAI em comparação aos alimentados com dietas à base de milho e farelo de soja. A inclusão de quirera de arroz na dieta não influenciou $(\mathrm{P}>0,05)$ o consumo de ração, o ganho de peso e a conversão alimentar (Tabela 4), o que está de acordo com o observado por Paranhos (1980).
Não houve interação $(\mathrm{P}>0,05)$ dos fatores estudados (subprodutos do arroz $\times$ conceitos de formulação) e somente o conceito de formulação promoveu efeito $(P<0,05)$ sobre o consumo de ração e a conversão alimentar. O ganho de peso não variou $(\mathrm{P}>0,05)$ entre os tratamentos. As aves alimentadas com as dietas formuladas com base na PI tiveram consumo de ração superior ( $115 \mathrm{~g}$ ou $2,55 \%$ a mais) aos daquelas alimentadas com dietas formuladas com base na $\mathrm{PB}$, o que possivelmente ocorreu em virtude do desbalanceamento da dieta, pois, segundo Harper (1976), quando as aves são alimentadas com dietas desbalanceadas, o mecanismo que regula o consumo pode ser modificado e ocasionar aumento na ingestão de alimento, em resposta a alterações no metabolismo energético ou em resposta à demanda crescente dos aminoácidos na ração.

Esperava-se uma melhora no ganho de peso das aves alimentadas com dietas formuladas com base na PI, pois, segundo Sakomura \& Silva (1998), estas dietas atenderiam mais eficientemente os requerimentos de aminoácidos que aquelas formuladas com base na concentração total de aminoácidos. Os resultados obtidos neste experimento diferem dos relatados por Mendoza et al. (2001), que constataram que dietas formuladas com base na PI e suplementadas com aminoácidos essenciais sintéticos, a fim de suprir as necessidades das aves, proporcionaram aumento significativo no ganho de peso.

A melhor conversão alimentar das aves alimentadas com dietas formuladas pelo conceito tradicional (PB) pode ser atribuída ao menor consumo de ração, uma vez que não houve diferença no ganho de peso. Esses resultados contrariam os relatos de Rostagno et al. (1995), que, em pesquisa com frangos de corte até os 42 dias de idade alimentados com dietas complexas formuladas com base na PB e PI e contendo 22,8 a 20,2\% de PB, observaram melhora na conversão alimentar dos frangos alimentados com dietas formuladas com base na PI.

Os motivos para a redução no desempenho das aves alimentadas com dietas de baixo conteúdo protéico e suplementadas com aminoácidos sintéticos ainda não estão bem esclarecidos e, segundo Bregendahl et al. (2002), as dietas com aminoácidos livres promovem menores concentrações de aminoácidos no sangue portal que aquelas com aminoácidos provenientes da proteína intacta, portanto, os aminoácidos livres são preferencialmente metabolizados pelos enterócitos e sua disponibilidade diminui em comparação aos aminoácidos na forma de peptídeos (proteína intacta). Segundo Pinchasov et al. (1990), essa menor taxa de absorção resultaria em menor disponibilidade de aminoácidos essenciais para síntese protéica. 
Não ocorreram interações subprodutos do arroz $x$ conceitos de formulação para rendimento de carcaça e de cortes; verificou-se diferença $(\mathrm{P}<0,05)$ para o peso relativo da gordura abdominal (Tabela 5) entre os conceitos de formulação adotados.

Tabela 4 - Desempenho de frangos de corte na fase de 1 a 42 dias de idade alimentados com dietas contendo subprodutos do arroz, formuladas com base nos conceitos de proteína bruta e ideal

\begin{tabular}{lccc}
\hline Item & \multicolumn{3}{c}{ Característica avaliada } \\
\cline { 2 - 4 } & CR (g) & GP (g) & CA \\
\hline Proteína & & & \\
\hline Bruta & $4.389 \mathrm{~b}$ & 2.566 & $1,71 \mathrm{~b}$ \\
Ideal & $4.504 \mathrm{a}$ & 2.518 & $1,79 \mathrm{a}$ \\
\hline Subproduto do arroz & & & \\
\hline AS & 4.434 & 2.511 & 1,77 \\
FAI & 4.411 & 2.534 & 1,74 \\
QA & 4.493 & 2.580 & 1,74 \\
\hline & & Valor de F & \\
\hline Proteína (Ptn) & $7,47^{*}$ & $0,85^{\mathrm{ns}}$ & $9,58^{*}$ \\
Subproduto do arroz (S) & $0,45^{\mathrm{ns}}$ & $0,57^{\mathrm{ns}}$ & $0,46^{\mathrm{ns}}$ \\
Ptn $\times$ S & $0,43^{\mathrm{ns}}$ & $0,95^{\mathrm{ns}}$ & $0,51^{\mathrm{ns}}$ \\
\hline CV (\%) & 3,81 & 4,74 & 3,32 \\
\hline
\end{tabular}

CR: consumo de ração; GP: ganho de peso; CA: conversão alimentar; SA: sem subproduto; FAl: farelo de arroz integral; QA: quirera de arroz. Médias na coluna seguidas de letras minúsculas diferentes são significativas $(P<0,05)$ pelo teste Tukey.

* $P<0,05$.

Tabela 5 - Rendimentos de carcaça (RC), de peito (RP), de coxa + sobrecoxa (RC+SC) e de gordura abdominal (GA) de frangos de corte aos 42 dias de idade alimentados com dietas contendo subprodutos do arroz, formuladas com base nos conceitos de proteína bruta e ideal

\begin{tabular}{ccccc}
\hline Item & \multicolumn{4}{c}{ Característica avaliada } \\
\cline { 2 - 5 } & RC & RP & RC + SC & GA \\
\hline
\end{tabular}

\begin{tabular}{lllll}
\hline Proteína & & & & \\
\hline Bruta & 71,60 & 31,20 & 33,40 & $1,65 \mathrm{~b}$ \\
Ideal & 72,00 & 32,00 & 33,37 & $2,06 \mathrm{a}$ \\
\hline
\end{tabular}

Subproduto do arroz

\begin{tabular}{lllll}
\hline SA & 71,87 & 31,10 & 32,60 & 1,78 \\
FAI & 71,90 & 31,60 & 33,54 & 1,90 \\
QA & 71,65 & 32,00 & 34,04 & 1,87 \\
\hline
\end{tabular}

Valor de F

\begin{tabular}{|c|c|c|c|c|}
\hline Proteína (Ptn) & $0,65^{\mathrm{ns}}$ & $2,89^{\mathrm{ns}}$ & $0,03^{\mathrm{ns}}$ & $21,27 *$ \\
\hline $\begin{array}{l}\text { Subproduto do } \\
\text { arroz (S) }\end{array}$ & $0,07^{\mathrm{ns}}$ & $1,22^{\mathrm{ns}}$ & $1,18^{\mathrm{ns}}$ & $0,64^{\mathrm{ns}}$ \\
\hline Ptn $\times S$ & $0,27^{\mathrm{ns}}$ & $1,04^{\mathrm{ns}}$ & $0,66^{\mathrm{ns}}$ & $1,51^{\mathrm{ns}}$ \\
\hline CV (\%) & 2,59 & 4,54 & 4,63 & 14,46 \\
\hline
\end{tabular}

SA: sem subproduto; FAl: farelo de arroz integral; QA: quirera de arroz. Médias na coluna seguidas de letras minúsculas diferentes são significativas $(P<0,05)$ pelo teste Tukey.
O farelo de arroz integral e a quirera de arroz não afetaram $(\mathrm{P}>0,05)$ o rendimento de carcaça e dos cortes nobres (peito, coxa + sobrecoxa) e o peso relativo da gordura abdominal. São escassos na literatura os achados quanto aos efeitos dos níveis de quirera de arroz em dietas para frangos de corte sobre o rendimento de carcaça, peito, coxa + sobrecoxa e peso relativo da gordura abdominal. No entanto, esses resultados corroboram os obtidos por Men et al. (1996), que, em pesquisa com patos, utilizaram dietas de nível fixo de quirera de arroz (60 e $80 \mathrm{~g} / \mathrm{dia}$ ) e ad libitum e observaram que os patos alimentados com maiores níveis de quirera na dieta apresentaram menores valores de rendimento de carcaça.

Considerando que o FAI é rico em alguns nutrientes, como proteína, lipídios e vitaminas B e E, sua utilização na alimentação de aves é limitada pela presença de fatores antinutricionais, como os polissacarídeos não-amiláceos (PNA). Segundo Cantor (1995), a porcentagem de PNA no FAI é bastante alta (25\%). Domene (1996) e Conte (2000) apontaram a presença de PNA no alimento como um efeito negativo sobre a absorção de nutrientes, o que justifica a piora no rendimento de carcaça e a redução na deposição de gordura abdominal das aves alimentadas com níveis crescentes de FAI. Francesh et al. (1994) afirmaram que os PNA interferem na absorção intestinal dos lipídios e provocam redução na deposição de gordura abdominal.

As aves alimentadas com dietas contendo maior teor protéico formuladas com base nos aminoácidos totais apresentaram menor percentual de gordura abdominal (19,9\%) em relação àquelas alimentadas com dietas com menor conteúdo protéico formuladas com base nos aminoácidos digestíveis. Este resultado provavelmente ocorreu porque a relação EM:PB é mais estreita nas dietas formuladas com base no conceito de $\mathrm{PB}$, uma vez que isto pode originar carcaças mais magras (Silva et al., 2003). Essa variação entre os tratamentos pode também ser explicada, em parte, pelo fato de a energia ser fornecida pelos compostos orgânicos da dieta ou ser derivada da desaminação de proteínas. Portanto, o fornecimento de proteína bruta em excesso ou de qualidade inferior sem o bom equilíbrio de aminoácidos pode implicar maior deposição de gordura (Leeson \& Summers, 1997). Portanto, maximizar a deposição de proteínas na ave permite atingir as exigências diárias de proteína, enquanto minimizar a deposição de gordura pode evitar a ingestão excessiva de energia em relação às necessidades para manutenção e crescimento. Resultados semelhantes foram observados por Bartov \& Plavnik (1998), Kerr \& Kidd (1999), Aletor et al. (2000) e Rezaei et al. (2004).

Rostagno et al. (1995) verificaram acréscimo de 2,10\% no rendimento de peito nas aves alimentadas com dietas 
formuladas com base na PI, o que não foi observado neste experimento. Os resultados deste experimento contrariam também os observados por Salmon et al. (1983), que forneceram dietas com baixo teor protéico para aves na fase inicial e verificaram menor rendimento de peito aos 42, 49 e 56 dias de idade.

\section{Conclusões}

A redução dos níveis de proteína bruta usados neste estudo (PI) não melhorou o desempenho zootécnico nem as características de carcaça de frangos abatidos aos 42 dias de idade. É possível usar o farelo de arroz integral e a quirera de arroz como ingredientes alternativos em dietas para frangos de corte.

\section{Literatura Citada}

ALETOR, V.A.; HAMID, I.I.; NIESS, E. et al. Low-protein amino acid-supplemented diets in broiler chickens: effects on performance, carcass characteristics, whole body composition and efficiencies of nutrient utilisation. Journal of the Science of Food and Agriculture, v.80, p.547-554, 2000.

ARAÚJO, L.F.; JUNQUEIRA, O.M.; ARAÚJO, C.S.S. et al. Proteína bruta e proteína ideal para frangos de corte no período de 1 a 21 dias de idade. Revista Brasileira de Ciência Avícola, v.3, n.2, p.157-162, 2001

ARAÚJO, L.F.; JUNQUEIRA, O.M.; ARAÚJO, C.S.S. Redução do nível protéico da dieta, através da formulação baseada em aminoácidos digestíveis. Ciência Rural, v.34, n.4, p.11971201, 2004

BARTOV, I.; PLAVNIK, I. Moderate excess of dietary protein increases breast meat yield of broiler chicks. Poultry Science, v.68, p.680-688, 1998.

BREGENDAHL, K.; SELL, J.L.; ZIMMERMAN, D.R. Effect of lowprotein diets on growth performance and body composition of broiler chicks. Poultry Science, v.81, n.8, p.1156-1167, 2002.

CANCHERINI, L.C.; JUNQUEIRA, O.M.; OLIVEIRA, M.C. et al. Utilização de subprodutos de origem animal em dietas formuladas com base em proteína bruta e proteína ideal para frangos de corte de 1 a 21 dias de idade. Revista Brasileira de Zootecnia, v.34, n.2, p.529-534, 2005.

COSTA, F.G.P.; ROSTAGNO, H.S.; ALBINO, L.F.T. et al. Níveis dietéticos de proteína bruta para frangos de corte de 1 a 21 dias e 22 a 42 dias. Revista Brasileira de Zootecnia, v.30, n.5, p.1498-1505, 2001.

CANTOR, A. Enzimas usadas na Europa, Estados Unidos e Ásia. Possibilidades para uso no Brasil. In: RONDA LATINOAMERICANA DE BIOTECNOLOGIA, 1995, Curitiba. Anais... Curitiba: 1995. p.31-42.

CONTE, A.J. Valor nutritivo do farelo de arroz em dietas para frangos de corte suplementadas com fitase e xilanase. Lavras: Universidade Federal de Lavras, 2000. 164p. Tese (Doutorado em Zootecnia) - Universidade Federal de Lavras, 2000.

DOMENE, S.M.A. Estudo do valor nutritivo mineral do farelo de arroz: utilização do zinco, ferro, cobre e cálcio pelo rato em crescimento. Campinas: Universidade Estadual de Campinas, 1996. 104p. Tese (Doutorado em Ciência da Nutrição) - Universidade Estadual de Campinas, 1996.

EMMERT, J.L.; BAKER, D.H. Use of the ideal protein concept for precision formulation of amino acid levels in broilers diets. Journal of Applied Poultry Research, v.6, p.462-470, 1997.
EUCLYDES, R.F. Sistema para Análises Estatísticas - SAEG. versão 7.1. Viçosa, MG: Fundação Arthur Bernardes, 1997. $59 \mathrm{p}$.

FARIA FILHO, D.E.; ROSA, P.S.; FIGUEIREDO, D.F. et al. Dietas de baixa proteína no desempenho de frangos criados em diferentes temperaturas. Pesquisa Agropecuária Brasileira, v.41, n.1, p.101-106, 2006.

FERGUSON, N.S.; GATES, R.S.; TARABA, J.L. et al. The effect of dietary crude protein on growth, ammonia concentration, and litter composition in broilers. Poultry Science, v.77, n.10, p.1481-1487, 1998.

FRANCESH, M.; PEREZ-VENDRELL, B.A.M.; ESTEVE-GARCIA, E. et al. Effects of cultiver pelleting and enzyme addition on nutritive value in poultry diets. British Poultry Science, v.35, p.259-272, 1994

GALLINGER, C.I.; SUÁREZ, D.M.; IRAZUSTA, A. Effects of rice bran inclusion on performance and bone mineralization in broiler chicks. Journal of Applied Poultry Research, v.13, p.183190, 2004.

GONZALES, E. Ingestão de alimentos: mecanismos regulatórios. In: MACARI, M.; FURLAN, R.L.; GONZALES, E. (Eds.) Fisiologia aviária: aplicada a frangos de corte. 2.ed. Jaboticabal: FUNEP, 2002. p.187-199.

HARPER, A.E. Proteins and amino acids in the regulation of food intake. In: NOVIN, D.; WYWICKA, W.; BRAY, G. (Eds.) Hunger: basic mechanisms and clinical implications. New York: Raven Press, 1976. p.103-113.

HUSSEIN, A.S.; CANTOR, A.H.; PESCATORE, A.J. et al. Effect of low protein diets with amino acid supplementation on broiler growth. Journal of Applied Poultry Research, v.10, n.4, p.354-362, 2001.

KERR, B.J.; KIDD, M.T. Amino acid supplementation of lowprotein broiler diets. 2. Formulation on an ideal animo acid basis. Journal of Applied Poultry Research, v.8, p.298309, 1999.

KESHAVARZ, K.; JACKSON, M.E. Performance of growing pullets and laying hens fed low-protein, amino acid supplemented diets. Poultry Science, v.71, p.905-918, 1992.

LEESON, S.; SUMMERS, J.D. Commercial poultry nutrition. Guelph: University Books, 1997, 350p.

MEN, B.X.; OGLE, B.; PRESTON, T.R. Use of restricted broken rice in duckweed based diets for fattening Common and Muscovy ducks. Livestock Research for Rural, v.8, n.3, 1996.

MENDOZA, M.O.B.; COSTA, P.T.C.; KATZER, L.H. et al. Desempenho de frangos de corte, sexados, submetidos a dietas formuladas pelos conceitos de proteína bruta versus proteína ideal. Ciência Rural, v.31, n.1, p.111-115, 2001.

PARANHOS, I.C.M. Utilização da quirera de arroz e do óleo de soja em rações de frangos de corte e poedeiras. Viçosa, MG: Universidade Federal de Viçosa, 1980. Dissertação (Nutrição em Zootecnia) - Universidade Federal de Viçosa, 1980.

PINCHASOV, Y.; MENDONÇA, C.X.; JENSEN, L.S. Broiler chick response to low protein diets supplemented with synthetic amino acids. Poultry Science, v.69, p.1950-1955, 1990.

REZAEI, M.; MOGHADDAM, N.; REZA, J.P. et al. The effects of dietary protein and lysine levels on broiler performance, carcass characteristics and $\mathrm{N}$ excretion. International Journal of Poultry Science, v.3, n.2, p.148-152, 2004.

ROSTAGNO, H.S.; PUPA, J.M.R.; PACK, M. Diet formulation for broilers based on total versus digestible amino acid. Journal Applied Poultry Research, v.4, p.293-299, 1995.

ROSTAGNO, H.S.; ALBINO, L.F.T.; DONZELE, J.L. et al. Tabelas brasileiras para aves e suínos: composição de alimentos $e$ exigências nutricionais. Viçosa, MG: Universidade Federal de Viçosa, 2000. 141p.

ROSTAGNO, H.S.; FEATHERSTON, W.R. Estudos de métodos para determinação de disponibilidade de aminoácidos. Revista da Sociedade Brasileira, v.6, p.64-76, 1977. 
SAKOMURA, N.K.; SILVA, R. Conceitos aplicáveis à nutrição de não ruminantes. Cadernos Técnicos da Escola de Veterinária da UFMG, v.22, p.125-146, 1998.

SALMON, R.E.; CLASSEN, H.L.; McMILLAN, R.K. Effect of starter and finisher protein on performance, carcass grade and meat yield of broilers. Poultry Science, v.62, p.837-845, 1983.

SIBBALD, I.R. A bioassay for the true metabolizable energy in feedstuffs. Poultry Science, v.55, p.303-308, 1976.

SILVA, J.H.V.; ALBINO, L.F.T.; NASCIMENTO, A.H. Estimativas da composição anatômica da carcaça de frangos de corte com base no nível de proteína da ração e peso da carcaça. Revista Brasileira de Zootecnia, v.32, n.2, p.344-352, 2003.

SUMMERS, J.D.; LESSON, S.; SPRATT, D. Yield and composition of edible meat from male broilers when fed diets varying in amino acid balance, dietary energy, and protein level. Poultry Science, v.71, p.263-273, 1992a.

SUMMERS, J.D.; SPRATT, D.; ATKINSON, J.L. Broiler weight gain and carcass composition when fed diets varying in amino acid balance, dietary energy and protein level. Poultry Science, v.71, p.263-273, $1992 b$. 